\title{
Publicidad y relaciones públicas en la promoción turística del Patronato Costa Blanca. 2008-2010
}

\author{
Ma Dolores Fernández Poyatos \\ Universidad de Alicante \\ dolores.fernandez@ua.es \\ Ainhoa Aguirregoitia Martínez \\ Universidad de Alicante \\ aguirregoitia.ainho@gmail.com
}

\section{Resumen:}

El Patronato Costa Blanca, organismo público encargado de la gestión turística de la provincia de Alicante, formaliza acciones de promoción, donde la comunicación turística -publicidad y relaciones públicas- adquiere un lugar destacado. El objetivo de esta investigación es conocer y valorar sus estrategias comunicativas entre los años 2008 y 2010. Tras el análisis, se constata la carencia de planes estratégicos de comunicación más amplios, donde se contemple el medio y largo plazo y donde se midan la eficacia de los programas desarrollados y las acciones utilizadas.

Palabras clave: publicidad turística; relaciones públicas; Patronato Turismo Costa Blanca Comunidad Valenciana; España.

\section{Advertising and public relations in the tourist promotion of the Costa Blanca Board. 2008-2010}

\begin{abstract}
:
The Costa Blanca Board, the public body responsible for the management of tourism in the province of Alicante, is in charge of formalising the promotion, in which tourist communication (advertising and public relations) takes a prominent place. The objective of this research is to understand and appreciate its communication strategies between 2008 and 2010. After the analysis, we note the lack of broaded strategic plans of communication, where the medium and long term can be taken into account and, also, where effectiveness of the programs developed and actions used can be determined.
\end{abstract}

Key Words: tourist advertising; public relations; Tourism Board Costa Blanca; Valencian Community; Spain.

\section{Referencia normalizada:}

Fernándes Poyatos, M. D. y Aguirregoitia Martínez, A. (2014): Publicidad y relaciones públicas en la promoción turística del patronato Costa Blanca. 2008 - 2010. Historia y Comunicación Social. Vol. 19. Núm. Especial Enero. Págs. 67-77.

Sumario: 1. Introducción. 2. Metodología. 3. Modelos de ordenación cronológica. 4. Conclusiones. 5. Referencias bibliográficas. 


\section{Introducción}

El turismo es uno de los sectores más relevantes para la Comunidad Valenciana; sin embargo, los estudios sobre la publicidad y las relaciones públicas en turismo apenas han tenido interés para la investigación. El Patronato Provincial de Turismo Costa Blanca, uno de los entes de promoción turística más importantes en el ámbito mediterráneo, tiene entre sus fines promover el turismo hacia la provincia de Alicante. En este contexto se inscribe nuestro trabajo, cuyo objetivo ha sido el de conocer y valorar las estrategias comunicativas de dicho organismo entre los años 2008 y 2010.

El ciclo positivo que el turismo español vivía desde los años 2004 y 2005 comenzó a dar síntomas de estancamiento en 2007 para quebrarse gravemente a lo largo de los dos años siguientes. Ante esta coyuntura, y con el objetivo de impulsar la economía, la Generalitat Valenciana elaboró diversos planes de competitividad y de marketing, donde las actuaciones comunicativas han ocupado un lugar destacado: El Plan de competitividad del sector turístico de la Comunitat Valenciana 2009-2011, el Plan de imagen y posicionamiento marketing 2009, el Plan de marketing turístico 2010 y el Plan estratégico global del turismo de la Comunidad Valenciana 2010-2020, que define la política turística para los próximos diez años.

El Patronato Provincial de Turismo Costa Blanca también estableció, entre 2008 y 2010, planes de competitividad para reactivar el sector; en ellos, la comunicación turística alcanza un lugar destacado. La revisión de dichos planes, así como el análisis de las acciones de publicidad y relaciones públicas constituyen el objeto de esta investigación.

\subsection{La investigación en comunicación turística}

La mayoría de los estudios sobre promoción del turismo provienen del ámbito del marketing (Bigné et alter, 2008), donde lo más relevante es su amplia productividad. Ahora bien, en lo que respecta a la comunicación publicitaria predomina el escaso número de trabajos: algunos abordan la imagen turística unida en ocasiones a la publicidad corporativa (Millán, Esteban, Molina y Martín, 2000); otros estudian la imagen de los destinos turísticos a través de su publicidad (Alonso, 2007).

Escasos son también los estudios sobre las comunidades autónomas, siendo la comunidad valenciana una de ellas (Bigné y Sánchez, 2001). Diversas investigaciones analizan la imagen que los turistas extranjeros tienen de las regiones españolas (Trujillo, López y Alarcón, 2002). Asimismo, se observa la función desempeñada por los mensajes publicitarios en la creación de la imagen de las comunidades autónomas en recientes estudios (Sánchez y Sanz Blas, 2003; Martín de la Rosa, 2003; Alonso, 2007; Solá, 2007).

En cuanto a las relaciones públicas, los estudios disminuyen aún más. Uno de los primeros fue el de Lías (1974) sobre la promoción de las agencias de viajes. Más actuales son los trabajos de Navarro (2001), que trata el marketing ferial como herramienta de promoción; el de Silva (2010), acerca de las ferias como espacios de 
comunicación, el de Míguez (2011), sobre las relaciones públicas en el Patronato de Turismo Rías Baixas y el de Fernández y Carretón (2011), que hacen lo propio con el Patronato de Turismo Costa Blanca. En general, se mencionan las acciones de relaciones públicas en turismo en los tratados de marketing como una herramienta más, y sin profundizar en ella.

Si consideramos las inversiones en comunicación turística - relaciones públicas y publicidad - de las empresas privadas y de los organismos públicos en nuestro país, y si se considera el importante papel que desempeñan en el sector, resulta difícil entender la escasez de trabajos, que se hace muy evidente en organismos como el Patronato de Turismo Costa Blanca (a partir de ahora, Patronato Costa Blanca), perteneciente a la Diputación Provincial de Alicante, y creado para gestionar las competencias de materia turística en la provincia de Alicante.

Éste es el motivo de que nuestro estudio se haya centrado en la comunicación turística de dicho organismo.

\section{Metodología}

Debido la importancia del sector turístico en la provincia de Alicante, y dada la referida ausencia de investigaciones sobre las acciones de comunicación turística, nuestro objetivo ha sido el conocer y valorar las estrategias comunicativas desarrolladas por el Patronato Costa Blanca. Para ello, se han analizado las actuaciones de publicidad y relaciones públicas, así como las acciones realizadas, atendiendo a los medios de comunicación utilizados - convencionales y no convencionales-, entre los años 2008 y 2010, esto es, cuando se produce la primera gran caída de turistas en España y los primeras señales de una tímida recuperación.

El proceso metodológico ha seguido las siguientes etapas:

- Se ha utilizado la Información de archivo, que se ha basado en:

- Análisis de contenido de los informes y planes de gestión del Patronato Costa Blanca de los años 2008 hasta 2010.

- Los datos incluidos en el portal del Patronato Costa Blanca, relativos a los contratos de servicios, suministros y otros.

- Los edictos publicados en el Boletín oficial de la provincia (BOP, desde ahora), concernientes a las acciones promocionales del Patronato Costa Blanca.

- Las noticias publicadas por el gabinete de prensa de la Diputación y del Patronato Costa Blanca.

- De forma paralela a la anterior, se ha realizado una revisión de la literatura sobre la comunicación turística en general y, en concreto, sobre la comuni- 
cación turística en Alicante, así como un análisis de los materiales gráficos y audiovisuales.

\section{La promoción turística de la costa blanca a través del patronato de turismo Costa Blanca}

Los patronatos de turismo - organismos públicos de gestión turística local en España - suponen casi el 19\% del total, financiándose básicamente con fondos públicos para el desempeño de sus funciones que, en general, se circunscriben a cuestiones relacionadas con la promoción y el desarrollo turísticos sin tener competencia en otros aspectos (Vera et alter, 2011). Este es el caso del Patronato Costa Blanca, creado para gestionar las competencias en materia turística que le atribuye la legislación, teniendo entre sus fines el de promover la presencia de la Costa Blanca en el mercado turístico, la promoción del turismo interior y exterior hacia la provincia de Alicante, la promoción de campañas de concienciación ciudadana y la edición y difusión del material orientado a la promoción turística.

Sus presupuestos entre los años 2008 y 2010 alcanzaron los 16.938 .730 euros; de ellos, 10.187.462,9 euros correspondieron al capítulo 2 (Gastos en bienes corrientes y servicios), que es el que recoge las acciones de promoción que dicho organismo desarrolla.

Las inversiones en promoción fueron incrementándose hasta 2009, cuando el presupuesto apenas se vio ampliado en 9.000 euros respecto a 2008. A partir de entonces, descendieron, siendo en 2010 de 2.884.637,10 euros (prácticamente la inversión del 2006), lo que significó 771.535,72 euros menos que el 2009.

Por otra parte, el Patronato recibe otras aportaciones de la Diputación, su ente matriz, que cuando lo considera necesario, administra fondos mediante el procedimiento de Modificación de créditos, y que entre 2008 y 2010 alcanzaron los 2.608.728,05 euros, siendo los años 2008 y 2009 los de mayores ingresos con más de un millón de euros cada uno. No obstante, y al igual que veíamos en la partida del capítulo 2 del año 2010, se produjo una caída de 700.000 euros respecto a los dos años precedentes.

La explicación a este recorte en los presupuestos del capítulo 2 reside, sobre todo, en el actual momento de contracción económica; sin embargo, es preciso decir también que mientras los presupuestos del Patronato Costa Blanca se congelaron los tres últimos años, la partida del capítulo 2 se rebajó más en términos relativos.

\subsection{La comunicación turística del patronato Costa Blanca}

Respecto a su área de promoción, el Patronato desarrolla actuaciones en ferias, fam y press trips, patrocinio y promoción. Las tres primeras se enmarcarían en el ámbito de las relaciones públicas y la última en el de la publicidad. Existen, sin embargo, 
interferencias semánticas entre los vocablos promoción, publicidad y relaciones públicas que en el mismo portal del Patronato se hacen evidentes cuando se engloban bajo el término promoción todas las actuaciones mencionadas para, después, limitar promoción a publicidad y publicity. En efecto, se describen como promoción las campañas publicitarias y la gestión de apariciones en medios televisivos, radiofónicos e impresos. En el primer caso se trataría de publicidad y, en el segundo, de publicity que, junto a las acciones que se refieren a continuación, se englobarían en las relaciones públicas. En nuestro trabajo, aunque diferenciamos las acciones descritas, consideramos dos amplias formas comunicativas: relaciones públicas y publicidad; incluidas en ellas estarían las demás, y todas integrarían el concepto comunicación.

\subsubsection{Acciones de relaciones públicas}

Hay que distinguir entre técnicas bidireccionales y unidireccionales; las primeras fluyen hacia, y desde, el público; las segundas se centran en una cobertura mediática positiva. Los fam y press trips, el patrocinio, las ferias, los road shows y los congresos son bidireccionales y la publicity, unidireccional (Xifra, 2008).

Respecto a los fam trips y press trips, llamados también viajes de familiarización, se preparan para que los profesionales del sector turístico, responsables de recomendar lugares turísticos, entren en contacto directo con el destino. Esta herramienta de promoción directa busca iniciar nuevos contactos y fortalecer los ya existentes en el lugar de destino; asimismo, permite comunicar los valores, las ventajas y otros complementos atractivos de un destino turístico.

Entre 2008 y 2010, el Patronato organizó un total de veintidós fam y press trips; casi todos se dirigieron a profesionales de mercados extranjeros y fueron llevados a cabo con la colaboración de organismos públicos y privados: la Cámara de Comercio, la Universidad de Alicante, las aerolíneas Sky Europe, Air Europe y Ryanair, el tour operador Olimar Reisen, la mayorista de viajes Jet 2.com y la organización del congreso Leading Campings of the World. Esta técnica de promoción ha sido una de las que ha experimentado un mayor crecimiento.

El patrocinio está considerado por el Patronato como una de las mejores y más efectivas formas de promocionar la provincia de Alicante como destino turístico, pues se logra difundir la marca Costa Blanca en los medios de comunicación. Sin embargo, desde el año 2009, sufrió un descenso relevante, ya que Conselleria de Turisme de la Generalitat lo redujo hasta un $56 \%$, en beneficio de otras formas prioritarias como las nuevas tecnologías y la publicidad.

El patrocinio más relevante fue el de Pau Gasol, quien desde 2005, y hasta el año 2011, fue la imagen promocional de Costa Blanca. Otro patrocinio se firmó con el tenista alicantino David Ferrer (Jávea), cuarto mejor jugador del mundo en el 2008. Por último, un tercer patrocinio se concertó con el también tenista alicantino Carlos Boluda para la temporada 2008. Está clara la notoriedad de los dos primeros, pero no la del tercero que se hallaba más allá del puesto 1.500 del ranking de la ATP World Tour. 
Con la asistencia a ferias nacionales e internacionales, el Patronato busca consolidar la imagen de la Costa Blanca y el incremento de visitantes. Su participación se realiza bien con stand propio, bien con la Conselleria de Turisme y(o) con Turespaña. En el caso de las internacionales, casi siempre acude con la Conselleria o Turespaña. Cuando se trata de ferias nacionales o sectoriales, suele hacerlo con stand propio y, en ocasiones, junto a la Conselleria.

En el período estudiado, asistió a cincuenta y dos certámenes, de los que treinta fueron internacionales. De éstas, repiten en el calendario las de BTL (Lisboa), ITB (Berlín), WTM (Londres) y Le Mond á Paris. Desde el 2009, se comenzó a acudir, ininterrumpidamente, a la Taste of Spain Travel Trade (Gran bretaña), la BIT y la EIBTM, en Barcelona. A la TUR (Goteborg) y a IGTM (Valencia) se empezó a asistir a partir del 2010.

En cuanto a las nacionales, entre 2008 y 2010 Fitur (con su sectorial Fitur congresos), Turismur, T.C.V., S.I.T.C., Expovacaciones, Intur y Lo mejor de la gastronomía se mantienen los tres años.

Además de presentar la oferta turística general y(o) complementaria de los productos más relevantes de la Costa Blanca (sol y playa, náutica, fiestas, golf, interior, gastronomía, cultura y salud), el objetivo de la desestacionalización ha sido primordial en la asistencias a las ferias referidas.

La técnica del road show consiste en una presentación de los valores de un producto o de una marca a los posibles compradores con la finalidad de crear el interés por dichos valores. Son de reciente incorporación, habiéndose realizado sólo dos —uno en 2009 y otro en 2010 - , antes de la temporada estival. El de 2009 se dirigió al público final y a intermediarios turísticos. El de 2010 acercó la oferta turística de la provincia de Alicante a más de 13.000 personas de Benidorm, Murcia, Albacete, Zaragoza, Valladolid, Valencia y Bilbao. La iniciativa se enmarcó dentro de la campaña Todos los colores del Mediterráneo, que el mismo Patronato impulsó con el objetivo de potenciar las reservas de última hora.

Hubo también otras acciones menos relevantes, conceptuadas como promoción directa que algunos autores consideran acciones de publicidad en medios no convencionales; otros las integran en las técnicas de RR.PP., y un tercer grupo las engloba en el marketing de proximidad. Lo que se pretende con ellas es la rapidez y personalización con el público al que se dirigen. Ese el caso de la campaña El dulce bienestar Mediterráneo para el mercado madrileño entre abril y mayo de 2010 que consistió en un stand ubicado en un centro comercial de Madrid, con degustaciones de productos con denominación de origen de la provincia.

\subsubsection{Acciones de publicidad}

El Patronato Costa Blanca desarrolló entre los años 2008 y 2010 diversas campañas de publicidad, donde sobresale el protagonismo del jugador de baloncesto Gasol. En efecto, y según consta en el Plan de actuación de 2008, el primer semestre del 
año se caracterizó por un descenso en la llegada de turistas de seis puntos porcentuales respecto al mismo período del año anterior. Ante esto, destaca la aprobación en septiembre de 2008 de una partida extraordinaria de 1,3 millones de euros con el fin de relanzar la imagen de la provincia en el último trimestre del año y paliar así la caída de la ocupación y, sobre todo, de la rentabilidad de los turistas que llegaron a la Costa Blanca.

A finales de ese mismo año, se lanzó la campaña Post Bejing '08 - Gigantes-, también con Gasol como prescriptor turístico. Su estrategia comunicativa, basada en el eslogan "Costa Blanca, un lugar hecho a tu medida", transmitió la idea de que la provincia de Alicante ofrecía, además de sol y playa, un conjunto diversificado y atractivo para ocupar el tiempo de ocio y descanso con propuestas muy variadas para todo tipo de público.

Otras campañas del 2008 se orientaron a los mercados británico, alemán y al de la Comunidad Valenciana. Con el primero se persiguió un doble objetivo: fortalecer la promoción turística en el período estival y reforzar el conocimiento de la provincia entre la población británica. Las campañas para el mercado alemán y para el mercado de la Comunidad Valenciana tuvieron el claro objetivo de la desestacionalización.

La población británica representaba el cincuenta y nueve por ciento de la cuota de mercado turístico en esta área respecto a la demanda internacional. Las campañas en el Reino Unido fueron dos; la primera - $A$ warm welcome awaits you (I) - , consistió en la emisión de un spot en cines, dando a conocer las bondades climáticas, turísticas y de ocio de la Costa Blanca. La segunda, también en cines, tuvo como objetivo reforzar el conocimiento de la provincia entre la población británica, principal mercado emisor de turistas extranjeros.

Para el mercado alemán se desarrolló otra entre 2008 y 2009 que persiguió el objetivo de incrementar y consolidar la llegada de turistas alemanes en temporada baja, aprovechando la existencia de vuelos directos de la compañía Air Berlin entre Costa Blanca y Alemania.

A mediados del 2009, y durante el año siguiente se cambió la estrategia comunicativa con una nueva campaña - "Todos los colores del Mediterráneo"-, que buscaba impactar a través de la emoción. En ella, se mostraban diversos destinos de Costa Blanca, así como productos complementarios — gastronomía, salud, cultura-, junto al producto sol y playa.

Para el mercado británico se desarrolló una campaña propia , It's already summer!, en diez ciudades del Reino Unido con conexión directa con el aeropuerto de El Altet (Alicante).

Ya en septiembre de 2010, y coincidiendo con el mundial de baloncesto en Turquía, se contrataron sobreimpresiones en pantalla de la campaña "Todos los colores del Mediterráneo", con marcas turísticas de la Costa Blanca: Alicante, Benidorm, Calpe, Denia, Jávea y Torrevieja. Se promocionaron los principales atractivos turísticos de 
la Costa Blanca: las playas, el interior, la gastronomía, la cultura y el ocio, entre otros, así como la práctica de deportes náuticos, de montaña o de golf.

Una importante novedad respecto a otros años fue la entrada del Patronato en las redes sociales: Facebook, Twitter, YouTube y Minube, además de un blog corporativo. El objetivo fue integrar la Costa Blanca en el ámbito de la web 2.0 como nuevo soporte para interactuar de forma más directa con los usuarios, ofrecer un contenido más dinámico y viral, así como aumentar los canales de comunicación con el público".

A Facebook, el Patronato se unió en 2010; los usuarios pudieron acceder, desde entonces, a contenidos turísticos y corporativos. Por su parte, twitter se diseñó con las texturas de la campaña "Todos los Colores del Mediterráneo". El blog de la Costa Blanca se concibió como una herramienta ágil y dinámica de comunicación directa, con noticias turísticas de la provincia de Alicante y del sector. En el canal YouTube se incluyeron los vídeos de las campañas realizadas y material audiovisual turístico. Por último, Costa Blanca como omenzó una presencia activa en la red social de viajes Minube.com que contaba ya con más de un millón de usuarios.

Ese mismo año se difundió la campaña en medios online - El País y El Mundopara el mercado nacional, portales de viajes, así como en Google Adwords. También se creó una página web específica, www.todosloscoloresdelmediterraneo.com, con sorteos y concursos para los usuarios, que además ofrecía la posibilidad de acceder a una zona multimedia con vídeos, información e imágenes de la campaña promocional. Internet se consideró, según el Patronato, como un medio excelente para captar turistas de último minuto.

\section{Conclusiones}

A pesar de la existencia de planes de promoción turística y balances de gestión, el Patronato Costa Blanca carece de un plan estratégico de comunicación amplio, que contemple el medio y largo plazo y, sobre todo, que se mida la eficacia de los programas desarrollados, así como las acciones utilizadas y los objetivos logrados. Los planes desarrollados durante en los años analizados son generales, heterogéneos, en ocasiones poco precisos y con objetivos a corto plazo. Probablemente, ésta sea la conclusión más clara que resulta de nuestro trabajo y también la actuación más apremiante que hay de considerar el Patronato.

En cuanto a las acciones de comunicación implementadas, la presencia en ferias ha sido la más notable, y eso a pesar de que el mismo Patronato anunció en 2010 que iba a cambiar su estrategia con menor presencia en ferias, así como el formato de trabajo en materia de promoción en aras de acciones más directas que incidieran claramente en los destinos. Sin embargo, su representación en las ferias fue muy similar a la de años precedentes. 
En el calendario de los tres años analizados, se mantienen prácticamente las mismas ferias nacionales; por el contrario, las internacionales registran ciertas variaciones: unas desaparecen en 2009 y 2010 (Vakantiebeurs, Holiday World y Steps); otras se mantienen los tres años (BTL, ITB, WTB y MAP); un tercer grupo parece consolidarse desde 2009 (BIT, EIBTM y Taste of Spain Travel Trade) y algunas inician su presencia en 2010 (TUR, IGTM).

Sobre otras actuaciones de relaciones públicas como los fam/press trips y los road shows, hay que subrayar el importante incremento de los primeros en 2010, dirigiéndose en su mayoría a profesionales del mercado extranjero.

Por el contrario, el patrocinio, sobre todo el deportivo, ha ido reduciéndose marcadamente los dos últimos años. Esta acción se plantea, quizá, como la más controvertida. Por una parte, sería cuestionable su alto coste; por otra, determinados acuerdos con deportistas desconocidos o mal conocidos. No nos referimos a la notoriedad y reconocimiento del internacional Pau Gasol, sino de su nula implicación personal con la Costa Blanca (nacido en Barcelona, juega en la NBA). No obstante, lo más cuestionable es el desconocimiento que el organismo turístico posee del impacto y de los resultados alcanzados con los diferentes contratos de patrocinio; el acierto, o no, de esta fuerte inversión sólo puede valorarse si después es medida.

En lo referente a las acciones de publicidad, fueron diversas las campañas desarrolladas. La del 2008 está en relación con las de los dos años anteriores, cuando las protagonizaba Gasol. Las del año 2009 y 2010 muestran una continuidad en su planteamiento: mismo eslogan y permanencia en el tiempo, respetando así el principio de estabilidad que una marca turística ha de observar en su comunicación. Hay que señalar el cambio producido en la campaña entre un año y otro, ya que se mejora bastante el tosco estilo de la primera edición.

Hay que destacar también la correlación que se observa entre el cambio en la dirección del Patronato (dos diputados de turismo) y ciertos cambios en las acciones de publicidad. Mientras en la primera etapa (2008) dominan con claridad los medios convencionales, en la segunda (2009 y 2010) se desarrollan los no convencionales, sobresaliendo la edición de guías temáticas de diversos productos, la implementación de campañas para reservas de última hora y el protagonismo de internet, primero, y de las redes sociales, después; sobre todo, en el último año, lo que puede explicarse por el auge de las nuevas tecnologías, pero también por la reducción presupuestaria que referíamos y que obliga, en cierto modo, a la contratación de formas y soportes más económicos.

La competencia de destinos emergentes, la crisis económica, la saturación de mercados y de destinos y productos similares hacen imprescindible la elaboración e implementación de estrategias de comunicación, en que la definición de objetivos y públicos receptores, la selección de medios y herramientas de comunicación, así como su evaluación, sean tareas prioritarias y fundamentales. Es así como es posible conseguir, no sólo un rendimiento justo de la inversión, sino un aumento de la 
imagen, el prestigio y la notoriedad de una marca turística. Esta es, quizá, la ineludible actuación que deba acometer el Patronato Provincial de Turismo Costa Blanca.

\section{Bibliografía}

ALONSO, C. (2007). "La publicidad turística como agente mediático de influencia en la percepción de los territorios y otras líneas de investigación complementarias". En: Revista Palabra Clave, vol. 10, n 2, p. 107-190.

ALTÉS, C. (1997). Marketing y Turismo. Madrid: Síntesis.

ÁlvareZ, A. (2000). Publicidad en Comunidad. Así se construyó la imagen de la Comunidad de Madrid, aplicando las técnicas del marketing social. Madrid: Universidad Complutense.

ARAGAY, J.J. (1978). Marketing turístico: con especial incidencia en la publicidad turística. Madrid: Servicios editoriales y de empresa S.A.

BIGNÉ, J. E., FONT, X. y ANDREU, L. (2000). Marketing de destinos turístico. Madrid: Esic.

BIGNÉ, J. E. y SÁNCHEZ, M. I. (2001). "Evaluación de la Imagen de destinos turísticos: Una aplicación metodológica en la Comunidad Valenciana”. En: Revista Europea de Dirección y Economía de la Empresa, vol. 10, nº 3, p. 189-200.

BIGNÉ, J. E.; ANDREU, L.; SÁNCHEZ, M.A.; ALVARADO, A. (2008). "Investigación en marketing turístico: análisis de contenido sobre temas y metodologías" En: Pasos, revista de turismo y patrimonio cultural, vol. 6, nº 3, p. 391-398.

FERNÁNDEZ, M.D. y CARRETÓN, M.C. (2011). "Investigación sobre la estrategia de relaciones públicas para la promoción del turismo alicantino". En: Icono 14, n⿳ A6, p. 223-244.

LÍAS, D. (1974). "La promoción del turismo por las agencias de viajes: publicidad y relaciones publicas". En: Estudios turísticos, n ${ }^{\circ} 42$, p. 105-118.

MARTÍN, B. (2003). "La imagen turística de las regiones insulares: las islas como paraísos". En: Cuadernos de turismo, no 11, p. 127-137.

MÍGUEZ, M.I. (2010). "Relaciones Públicas 2.0 en el sector turístico: análisis de caso del Patronato de Turismo Rías Baixas". En: V Congreso Internacional de Investigación y Relaciones Públicas. Barcelona: Universidad Ramón Llull.

MILlÁN, Á, ESTEBAN, A., MOLINA, A. y MARTÍN, D. (2000). "Publicidad corporativa e imagen de los destinos turísticos". En BLANQUER, D. (coord.). Municipios turísticos, tributación y contratación empresarial, formación y gestión del capital humano. Valencia: Tirant Lo Blanch, p. 185-196.

NAVARRO, F. (2001). Estrategias de marketing ferial. Valencia: ESIC.

PATRONATO PROVINCIAL DE TURISMO COSTA BLANCA. Informe de gestión de 2003-2007. Alicante : Patronato Provincial de Turismo Costa Blanca, 2007.

PATRONATO PROVINCIAL DE TURISMO COSTA BLANCA. Plan de actuación Patronato Provincial de Turismo Costa Blanca. Cuarto trimestre 2008.

PATRONATO PROVINCIAL DE TURISMO COSTA BLANCA. Balances 2009 y 2010. 
SÁNCHEZ, I. y SANZ, S. (2003). "El Papel de la promoción turística en la construcción de la imagen de un destino". En: BLANQUER, D. (coord.). Turismo cultural y urbano. Valencia: Tirant Lo Blanch, p. 463-480.

SOLÁ, R. (2007). Análisis de las estrategias publicitarias de las campañas turísticas de la Comunidad Valenciana 1989-2006. Tesis doctoral dirigida por Rafael López Lita. Castellón: Universidad Jaume I de Castellón.

VERA, JF., LÓPEZ, F., MARCHENA, M., ANTÓN, S. (2011). Análisis territorial del turismo y planificación de destinos turísticos. València: Tirant Lo Blanch.

TRUJILLO, F., LÓPEZ, P. y ALARCÓN, P. (2002). "Imagen turística de las Comunidades Autónomas españolas ante una demanda segmentada". En: Estudios de economía aplicada, vol. 20, p. 627-649.

XIFRA, J. (2008). Técnicas de las relaciones públicas. Barcelona: UOC.

\section{Las autoras}

$\mathrm{M}^{\mathrm{a}}$ Dolores Fernández Poyatos es Doctora por la Universidad de Alicante. Profesora del Dpto. de Comunicación y Psicología social (Universidad de Alicante); investigadora en diversos proyectos de investigación y autora de diversas publicaciones. Desarrolla su actividad docente e investigadora en el área de la Publicidad y las relaciones públicas en turismo, la Historia de la publicidad y la Estrategia de la comunicación publicitaria.

Ainhoa Aguirregoitia Martínez es Licenciada en Publicidad y Relaciones Públicas por la Universidad de Alicante. Doctoranda del Instituto de Investigaciones Turísticas de la UA. Actualmente desarrolla su trabajo como Secretaria Académica en el Máster de Dirección de Restaurantes y F\&B Hotelero. 